\title{
Resposta do arroz irrigado ao fornecimento de fósforo e densidade de semeadura em sistema pré-germinado
}

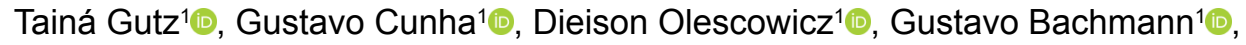

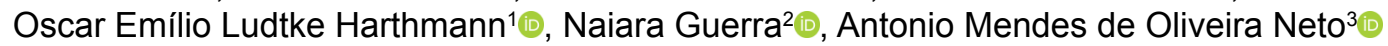

\footnotetext{
1 Instituto Federal Catarinense, Campus Rio do Sul, Rio do Sul, SC, Brasil. E-mail: tainagutz.tg@gmail.com; agronomia.cunha@gmail.com; dieisonoles@gmail.com; guu.rls@gmail.com; oscar.harthmann@ifc.edu.br

${ }^{2}$ Universidade Federal de Santa Catarina, Campus de Curitibanos, Curitibanos, SC, Brasil. E-mail: naiaraguerra.ng@gmail.com

${ }_{3}^{3}$ Universidade do Estado de Santa Catarina, Centro de Ciências Agroveterinárias, Lages, SC, Brasil. E-mail: am.oliveiraneto@gmail.com
}

RESUMO: O arroz irrigado apresenta elevada importância socioeconômica para o estado de Santa Catarina, contudo, estudos que visam a definição da densidade de semeadura e a resposta do arroz irrigado ao fornecimento de fósforo ainda são escassos. Desta maneira, este trabalho teve como objetivo avaliar a produtividade do arroz irrigado, conduzido em sistema pré-germinado, em função da densidade de semeadura e da adubação fosfatada. $O$ experimento foi conduzido em blocos casualizados e os tratamentos foram arranjados em esquema fatorial $4 \times 3$, com quatro repetições. Foram testadas quatro densidades de semeadura da cultivar SCS $121 \mathrm{CL}\left(60,90,120\right.$ e $\left.150 \mathrm{~kg} \mathrm{ha}^{-1}\right)$ e três dosagens de fósforo $\left(0,25\right.$ e $\left.50 \mathrm{~kg} \mathrm{ha}^{-1} \mathrm{de}_{2} \mathrm{O}_{5}\right)$. As variáveis avaliadas foram: número de colmos por metro quadrado, número de panículas por metro quadrado, número de panículas por planta, produtividade de grãos e o peso de mil grãos. Os resultados indicam que a supressão da adubação fosfatada pode comprometer componentes de produção importantes, como o número de panículas por $\mathrm{m}^{2} \mathrm{e}$ o peso de mil grãos. Contudo, os fatores densidade de semeadura e dosagem de fósforo não influenciaram a produtividade de grãos.

Palavras-chave: Alto Vale do Itajaí; componentes de rendimento; Oryza sativa

\section{Paddy rice response to phosphorus supply and sowing density in pre-germinated system}

ABSTRACT: Paddy rice present elevated importance socioeconomic in Santa Catarina State, however, research about the sowing density and paddy rice response to phosphorus supply are scarce. Thus, this work was the objective to evaluate the paddy rice yield, cultivated in pre-germinated system, in function of sowing density and phosphate fertilization. Experiment was conduct in blocks completely randomized and the treatments are arrange in factorial scheme $4 \times 3$, with four replications. Was test four sowing density of SCS $121 \mathrm{CL}$ cultivar $\left(60,90,120\right.$ and $\left.150 \mathrm{~kg} \mathrm{ha}^{-1}\right)$ and three phosphorus rates $\left(50,25 \mathrm{e} 0 \mathrm{~kg} \mathrm{ha}^{-1}\right.$ of $\mathrm{P}_{2} \mathrm{O}_{5}$ ). The variable evaluated were number of stems per meter square, number of panicle per plant, yield and thousand-grain weight. The results indicated that phosphate fertilization reduce can compromise the important yield compounds, like number of panicle per meter square and thousand-grain weight. Yet, the factors sowing density and phosphorus rate not influence the yield.

Key words: High Valley of Itajaí; yield components; Oryza sativa 


\section{Introdução}

A cultura do arroz se destaca como uma das mais importantes no mundo, sendo considerada como um produto de importância econômica e social, em função de sua ampla adaptabilidade, resposta à aplicação de tecnologias e diversas formas de cultivo (Sartori et al., 2011). A produção média brasileira na safra 2016/17, 2017/18 e 2018/19 foi de 10,953; 12,064 e 10,653 milhões de t, respectivamente. Em Santa Catarina a produção foi de 1,098; 1,151 e 1,083 milhão de t, nas safras 2016/17, 2017/18 e 2018/19, respectivamente (Conab, 2018).

No Estado de Santa Catarina o pré-germinado é o sistema de cultivo predominante, sendo adotado em cerca de $80 \%$ da área cultivada no Estado (Epagri, 2015). O planejamento deste sistema de produção é parte fundamental para a obtenção de altas produtividades, e neste sentido, itens como a escolha da cultivar adaptada as condições de produção, elevada qualidade fisiológica de sementes, definição criteriosa do arranjo de plantas, manejo racional da fertilidade, controle de plantas daninhas, pragas e doenças são de fundamental importância. De acordo com a Epagri (2015), estes têm sido os principais responsáveis pela evolução da orizicultura catarinense, tanto no contínuo acréscimo em produtividade como na qualidade do produto colhido.

Neste sentido, a obtenção de adequada população de plantas é um dos principais fatores de definição da produtividade, pois influenciam na prevenção da ocorrência de doenças, uniformização da maturação e evita o acamamento das plantas. A densidade recomendada é bastante generalizada, e compreende a faixa de 150 a 300 plantas $\mathrm{m}^{-2}$, o equivalente a semeadura de 80 a $120 \mathrm{~kg} \mathrm{ha}^{-1} \mathrm{de}$ sementes (Sosbai, 2016).

No sistema pré-germinado o solo é revolvido e a entrada de água ocorre simultaneamente ao preparo. Sob condições de inundação do solo, inúmeras são as alterações eletroquímicas que ocorrem, principalmente em relação à decomposição anaeróbica da matéria orgânica, verificando-se alterações e transformações na disponibilidade de íons na água de drenagem e na solução do solo (Swarowsky et al., 2006).

A condição anaeróbica do solo, resultante da inundação, acarreta em severas alterações químicas no ambiente da rizosfera do arroz. A principal alteração é a redução do potencial redox do solo e o aumento na concentração de ferro (na forma de $\mathrm{Fe}^{2+}$ ) e manganês (na forma de $\mathrm{Mn}^{2+}$ ). Em solos ácidos, como os brasileiros, ocorre a elevação no valor do $\mathrm{pH}$, o que é conhecido como autocalagem. Outra consequência do ambiente anaeróbico é a redução de nitrato e dióxido de nitrogênio em dinitrogênio e óxido nitroso, do sulfato para sulfito e do dióxido de carbono para metano. A inundação do solo contribui com o aumento na concentração de elementos minerais como fósforo, cálcio, magnésio, ferro, manganês, molibdênio e silício. Por outro lado, os teores de zinco, cobre e enxofre decrescem no ambiente anaeróbico (Fageria et al., 2011). No caso do fósforo, a sua disponibilidade na solução aumenta com a inundação em função da redução do fosfato férrico, para formas mais solúveis de ferro e pela hidrólise dos componentes do fosfato, sendo este processo mais acentuado em solos ácidos, onde o fósforo é imobilizado em óxidos de ferro e alumínio (Fageria \& Barbosa Filho, 2007).

Munidos destas informações e em função da ampla adoção do sistema de cultivo pré-germinado, onde a inundação da área inicia na fase de preparo do solo, alguns técnicos vêm recomendando, de maneira empírica, a suspensão da adubação fosfatada em condições em que o solo possua o teor mínimo de 6,0 $\mathrm{mg} \mathrm{dm}^{-3}$ de fósforo. Evidente que pode ser uma decisão arriscada já que o fósforo é apontado como um dos nutrientes mais limitantes para a produção de arroz irrigado (Silva et al., 2008; Fageria et al., 2013), além de ser o nutriente de maior exportação percentual na produção de arroz em casca e o mais deficiente na maioria dos solos brasileiros, devido ao baixo teor natural e a alta capacidade de fixação (Crusciol et al., 2005). Alguns estudos revelaram a correlação positiva entre a adubação com fósforo, componentes de produção e produtividade de grãos de arroz irrigado (Wissuva \& Ae, 2001; Sant'ana et al., 2003; Crusciol et al., 2005; Fageria et al., 2013; Nascente et al., 2014).

Baseado na problemática apresentada, a hipótese inicial deste trabalho foi de que a suspensão da adubação fosfatada de maneira empírica pode prejudicar o rendimento da cultura, principalmente quando realizada em áreas com baixo nível de fertilidade e em baixas densidades de semeadura. Por conseguinte, esta pesquisa teve como objetivo avaliar a produtividade de arroz irrigado conduzido em sistema pré-germinado implantado em diferentes densidades de semeadura e doses de fósforo.

\section{Material a Métodos}

O experimento foi conduzido no período de outubro de 2016 a maio de 2017, em área comercial sistematizada para a produção de arroz irrigado em sistema pré-germinado, localizada no município de Pouso Redondo, SC, no distrito de Corruchel $\left(27^{\circ} 18^{\prime} 44,7^{\prime \prime}\right.$ S e $\left.49^{\circ} 57^{\prime} 40,7^{\prime \prime} O\right)$. O clima da região é subtropical úmido (classificação climática de Köppen-Geiger: (fa), a distribuição da precipitação ao longo da condução do experimento está na Figura 1. O solo da área é classificado como Cambissolo Háplico distrófico gleico de textura argilosa (Embrapa, 2013). A análise química do solo, na camada de 0 a $20 \mathrm{~cm}$ de profundidade, apresentou $\mathrm{pH}$ em água de 4,2; 24,1 cmolc $\mathrm{dm}^{-3}$ de $\mathrm{H}^{+}+\mathrm{Al}^{3+} ; 111,6 \mathrm{cmolc} \mathrm{dm}^{-3}$ de $\mathrm{K}^{+} ; 3,0 \mathrm{cmolc} \mathrm{dm}^{-3}$ de $\mathrm{Ca}^{2+}, 0,7 \mathrm{cmolc} \mathrm{dm}^{-3}$ de $\mathrm{Mg}^{2+} ; 3,8 \mathrm{mg} \mathrm{dm}^{-3}$ de $\mathrm{P}, 28 \mathrm{~g} \mathrm{~kg}^{-1}$ de MO, V\% de 14,28, $500 \mathrm{~g} \mathrm{~kg}^{-1}$ de argila, $290 \mathrm{~g} \mathrm{~kg}^{-1}$ de silte e 210 $\mathrm{g} \mathrm{kg}^{-1}$ de areia.

O delineamento do experimento foi em blocos completos ao acaso e os tratamentos foram arranjados em esquema fatorial $4 \times 3$, com quatro repetições. Foram testadas quatro densidades de semeadura da cultivar SCS $121 \mathrm{CL}(60,90,120$ e $150 \mathrm{~kg} \mathrm{ha}^{-1}$ ) e três dosagens de adubação fosfatada (0, 25 e $50 \mathrm{~kg} \mathrm{ha}^{-1}$ de $\mathrm{P}_{2} \mathrm{O}_{5}$ ), resultando em 12 tratamentos, sendo que cada unidade experimental apresentou área total de $15 \mathrm{~m}^{2}$. 


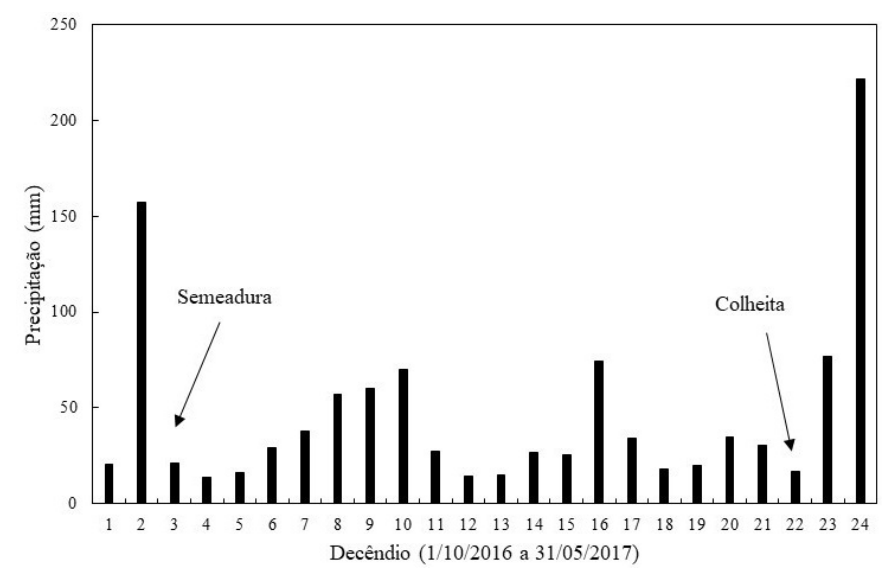

Figura 1. Precipitação acumulada por decêndio $(\mathrm{mm})$ no período de 1/10/2016 a 31/05/2017. Estação pluviométrica do bairro Itoupava em Rio do Sul. Rio do Sul, SC, 2018/2019. (Cemaden, 2019).

O sistema de produção adotado foi o pré-germinado. $O$ solo foi preparado aproximadamente 30 dias antes da semeadura. A primeira operação realizada foi a incorporação dos resíduos culturais com o auxílio do rolo faca, na sequência o preparo do solo e formação da lama foram realizadas com duas operações com a enxada rotativa, sendo a última realizada com o solo inundado. Após a formação da lama o leito de semeadura foi nivelado com o auxílio de uma prancha niveladora e por fim estabeleceu-se uma lâmina de água de aproximadamente cinco centímetros para realização da semeadura.

As sementes foram imersas em água por 24 horas e, em seguida, foram deixadas a sombra por 48 horas para que ocorresse a pré-germinação. A área foi previamente inundada e a semeadura foi realizada manualmente no dia 31 de outubro de 2016, conforme a densidade de semeadura do tratamento.

A recomendação de adubação foi realizada de acordo com a interpretação da análise de solo da área, seguindo as recomendações da Sosbai (2016), prevendo um rendimento de grãos maior que sete $\mathrm{t} \mathrm{ha} \mathrm{a}^{-1}$, conforme o histórico da área. Para tanto foram aplicados, em cada parcela, o equivalente a $110 \mathrm{~kg} \mathrm{ha}^{-1}$ de nitrogênio $(\mathrm{N})$, usando ureia (45\% de N) e $50 \mathrm{~kg} \mathrm{ha}^{-1}$ de potássio $\left(\mathrm{K}_{2} \mathrm{O}\right)$ usando como fonte cloreto de potássio $\left(60 \% \mathrm{~K}_{2} \mathrm{O}\right)$. Nas parcelas testemunhas não foi aplicado adubação fosfatada (0 kg ha-1 de $\left.\mathrm{P}_{2} \mathrm{O}_{5}\right)$, nas parcelas com metade da dose, $25 \mathrm{~kg} \mathrm{ha}^{-1}$ de $\mathrm{P}_{2} \mathrm{O}_{5}$, e as que continham a dosagem completa de fósforo foi aplicado o equivalente a 50 $\mathrm{kg} \mathrm{ha}^{-1}$ de $\mathrm{P}_{2} \mathrm{O}_{5}$, a fonte de fósforo utilizada foi o superfosfato triplo ( $45 \%$ de $\mathrm{P}_{2} \mathrm{O}_{5}$ ). A adubação nitrogenada foi dividida em três aplicações: $50 \mathrm{~kg} \mathrm{ha}^{-1}$ no estádio $V_{4^{\prime}}, 30 \mathrm{~kg} \mathrm{ha}^{-1}$ no estádio $\mathrm{V}_{7}-\mathrm{V}_{8}$ e $30 \mathrm{~kg} \mathrm{ha}^{-1}$ no estádio $\mathrm{R}_{0}$. Enquanto a adubação potássica e a fosfatada foram realizadas integralmente no estádio de desenvolvimento $\mathrm{V}_{4}$.

O método químico foi adotado para controlar as plantas daninhas, como a tiririca (Cyperus spp.), capim-arroz (Echinochloa spp.) e sagitária (Sagittaria montevidensis), para tanto foram aplicados os seguintes herbicidas: Basagran ${ }^{\circ}(2$ $\left.\mathrm{L} \mathrm{ha}^{-1}\right)$, Ricer $\left(0,2 \mathrm{~L} \mathrm{ha}^{-1}\right)$ e Aurora $\left(0,08 \mathrm{~L} \mathrm{ha}^{-1}\right)$. Todos foram aplicados quando o arroz irrigado estava no estádio $\mathrm{V}_{4^{\prime}}$, com adição de óleo vegetal $\left(0,5 \mathrm{~L} \mathrm{ha}^{-1}\right)$.

Ao final do ciclo, no estádio $R_{2}-R_{3}$, foi feita a aplicação do inseticida Talisman $\left(0,3 \mathrm{~L} \mathrm{ha}^{-1}\right)$ para o controle do percevejodo-colmo (Tibraca limbativentis) e percevejo-do-grão (Oebalus poecilus) e para o controle de brusone (Pyricularia grisea) foi realizada a aplicação preventiva dos fungicidas Bim ${ }^{\circ}$ $\left(0,3 \mathrm{~kg} \mathrm{ha}^{-1}\right)$ e Nativo ${ }^{\circ}\left(0,75 \mathrm{~L} \mathrm{ha}^{-1}\right)$. A colheita foi realizada aos 157 dias após a semeadura, de forma manual, colhendo uma em cada parcela de $4,5 \mathrm{~m}^{2}$.

As variáveis avaliadas foram: número de colmos por metro quadrado, número de panículas por metro quadrado e o número de panículas por planta, todas realizadas no estádio $R_{6}$. O peso de mil grãos e produtividade de grãos foram avaliados no estádio $R_{9}$. Determinou-se o teor de umidade dos grãos em cada parcela com o auxílio de um medidor de umidade de bancada, sendo a umidade padronizada para $130 \mathrm{~g} \mathrm{~kg}^{-1}$. O peso de mil grãos (PMG) foi determinado de acordo com a metodologia descrita nas Regras de Análises de Sementes (Brasil, 2009).

Os resultados obtidos foram submetidos ao teste de normalidade de Shapiro-Wilk ( $p=0,05)$, posteriormente realizou-se a análise de variância pelo teste $F$. A variável densidade de semeadura foi submetida a análise de regressão polinomial. Já a dose de fósforo foi comparada pelo teste de Tukey. O nível de significância adotado foi de até $5 \%(p=0,05)$.

\section{Resultados e Discussão}

As variáveis número de colmos por $\mathrm{m}^{2}$, número de panículas por $\mathrm{m}^{2}$, a produtividade e o peso de mil sementes apresentaram valores não significativos quando submetidas ao teste de normalidade Shapiro-wilk, assim pode-se afirmar que, com nível de significância de até $5 \%$, as amostras provêm de uma população normal. A variável panículas por planta não apresentou normalidade, realizou-se então a transformação dos dados originais para $\mathrm{V} x$, mas o conjunto não atendeu a normalidade, desta forma optou-se por não apresentar os resultados desta variável.

A interação densidade de semeadura e dose do fósforo ( $D$ $\mathrm{X}$ P) foi não significativa para todas as variáveis, assim como o fator isolado dose de fósforo (P) (Tabela 1). De maneira semelhante, em sua pesquisa, Reis et al. (2018) relataram que em condições de alta fertilidade do solo ( $P$ de $13,0 \mathrm{mg} \mathrm{kg}^{-1}$ e $380 \mathrm{~g} \mathrm{~kg}^{-1}$ de argila) os componentes de produtividade do arroz irrigado não foram influenciados pelo fósforo.

Observou-se diferenças significativa apenas para o fator densidade de semeadura (D), para as variáveis número de colmos por $\mathrm{m}^{2}$ e número de panículas por $\mathrm{m}^{2}$ (Tabela 1). Mesmo com a interação $D$ x $P$ não sendo significativa, procedeu com os desdobramentos dos fatores, conforme apresentado na Tabela 1. Este procedimento foi realizado com o objetivo de explorar a análise por comparação, evitando a perda de informações relevantes, conforme apresentado por Perecin \& Cargnelutti Filho (2008). 
Tabela 1. Resumo da análise de variância. Pouso Redondo, SC, 2016/2017.

\begin{tabular}{ccccc}
\hline Fonte variação & F colmos m $^{2}$ & F panícula $~^{2}$ & F produtividade & F PMG \\
\hline Densidade (D) & $7,25^{*}$ & $5,03^{*}$ & $0,36^{\text {ns }}$ & $1,99^{\text {ns }}$ \\
Fósforo (P) & $0,56^{\text {ns }}$ & $0,34^{\text {ns }}$ & $2,41^{\text {ns }}$ & $0,12^{\text {ns }}$ \\
D x P & $0,86^{\text {ns }}$ & $1,61^{\text {ns }}$ & $0,98^{\text {ns }}$ & $0,47^{\text {ns }}$ \\
D/P0 & $5,08^{*}$ & $5,52^{*}$ & $0,69^{\text {ns }}$ & $0,95^{\text {ns }}$ \\
D/P25 & $2,24^{\text {ns }}$ & $1,47^{\text {ns }}$ & $0,77^{\text {ns }}$ & $0,33^{\text {ns }}$ \\
D/P50 & $1,66^{\text {ns }}$ & $1,25^{\text {ns }}$ & $0,86^{\text {ns }}$ & $0,52^{\text {ns }}$ \\
P/D60 & $0,66^{\text {ns }}$ & $2,83^{\text {ns }}$ & $1,98^{\text {ns }}$ & $0,58^{\text {ns }}$ \\
P/D90 & $0,27^{\text {ns }}$ & $0,86^{\text {ns }}$ & $0,89^{\text {ns }}$ & $0,32^{\text {ns }}$ \\
P/D120 & $1,91^{\text {ns }}$ & $1,23^{\text {ns }}$ & $2,34^{\text {ns }}$ & $0,12^{\text {ns }}$ \\
P/D150 & $0,35^{\text {ns }}$ & $0,24^{\text {ns }}$ & $0,14^{\text {ns }}$ \\
\hline
\end{tabular}

* = significativo $(p<0,05)$ e ns $=$ não significativo $(p \geq 0,05)$

$P M G=$ peso de mil grãos, $\mathrm{PO}=0 \mathrm{~kg}$ ha- ${ }^{-1}$ de $\mathrm{P}_{2} \mathrm{O}_{5}, \mathrm{P} 25=25 \mathrm{~kg} \mathrm{ha}^{-1}$ de $\mathrm{P}_{2} \mathrm{O}_{5}, \mathrm{P} 50=50 \mathrm{~kg} \mathrm{ha}^{-1}$ de $\mathrm{P}_{2} \mathrm{O}_{5}, \mathrm{D} 60=60 \mathrm{~kg}$ ha ${ }^{-1}$ de sementes, D90 $=90 \mathrm{~kg}$ ha ${ }^{-1}$ de sementes, $\mathrm{D} 120=120 \mathrm{~kg}$ ha ${ }^{-1}$ de sementes e $\mathrm{D} 150=150 \mathrm{~kg} \mathrm{ha}^{-1}$ de sementes.

Na Tabela 2 está o resumo da análise de regressão para a densidade de semeadura e densidade de semeadura em cada dose de fósforo. Observou-se significância do modelo linear para o número de colmos $\mathrm{m}^{2}$ para o fator densidade de semeadura e densidade de semeadura com as doses de 0 e 25 $\mathrm{kg} \mathrm{P}_{2} \mathrm{O}_{5} \mathrm{ha}^{-1}$. Este mesmo modelo se ajustou para o número de panículas por $\mathrm{m}^{2}$ para o fator densidade de semeadura e densidade de semeadura com a dose de $0 \mathrm{~kg} \mathrm{P}_{2} \mathrm{O}_{5} \mathrm{ha}^{-1}$. Para a variável peso de mil grãos houve ajuste do modelo quadrático para o fator densidade de semeadura e densidade

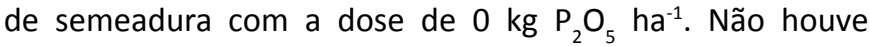
ajuste significativo dos modelos de regressão polinomial para variável produtividade de grãos.

O número médio de colmos por $\mathrm{m}^{2}$ apresentou incremento linear em função da densidade de semeadura (Figura 2A), havendo acréscimo de 1,2644 colmos por $\mathrm{m}^{2}$ para cada quilograma de semente adicionado. Estes resultados corroboram com os relatos de Lima et al. (2010), para a cultivar IAC 102, onde constataram que o número de colmos principais por $\mathrm{m}^{2}$ aumentou a medida em que a densidade de

Tabela 2. Resumo da análise de regressão. Pouso Redondo, SC, 2016/2017.

\begin{tabular}{|c|c|c|c|c|}
\hline Causa variação & D & $\mathrm{D} / \mathrm{PO}$ & D/P25 & D/P50 \\
\hline & \multicolumn{4}{|c|}{ № Colmos $\mathrm{m}^{2}$} \\
\hline Linear & $20,83^{*}$ & $14,70^{*}$ & $4,55^{*}$ & $3,76^{\text {ns }}$ \\
\hline Quadrático & $0,87^{\mathrm{ns}}$ & $0,00^{\text {ns }}$ & $0,26^{\text {ns }}$ & $1,15^{\text {ns }}$ \\
\hline \multirow[t]{2}{*}{ Desvio regressão } & $0,05^{\text {ns }}$ & $0,54^{\text {ns }}$ & $1,91^{\text {ns }}$ & $0,07^{n s}$ \\
\hline & \multicolumn{4}{|c|}{ № Panículas m² } \\
\hline Linear & $14,92 *$ & $14,30 *$ & $3,54^{\text {ns }}$ & $1,06^{\text {ns }}$ \\
\hline Quadrático & $0,19^{\text {ns }}$ & $2,05^{\text {ns }}$ & $0,30^{\text {ns }}$ & $2,09^{n s}$ \\
\hline \multirow[t]{2}{*}{ Desvio regressão } & $0,07^{\text {ns }}$ & $0,22^{\text {ns }}$ & $0,58^{\text {ns }}$ & $0,61^{\text {ns }}$ \\
\hline & \multicolumn{4}{|c|}{ Produtividade $\left(\mathrm{kg} \mathrm{ha}^{-1}\right)$} \\
\hline Linear & $0,33^{\text {ns }}$ & $0,50^{\text {ns }}$ & $2,17^{\text {ns }}$ & $0,05^{\text {ns }}$ \\
\hline Quadrático & $0,38^{\text {ns }}$ & $0,83^{\text {ns }}$ & $0,00^{\text {ns }}$ & $0,06^{\text {ns }}$ \\
\hline \multirow[t]{2}{*}{ Desvio regressão } & $0,38^{\text {ns }}$ & $0,74^{\text {ns }}$ & $0,12^{\text {ns }}$ & $2,48^{\text {ns }}$ \\
\hline & \multicolumn{4}{|c|}{ PMG (g) } \\
\hline Linear & $0,45^{\text {ns }}$ & $0,68^{\text {ns }}$ & $0,64^{\text {ns }}$ & $0,21^{\text {ns }}$ \\
\hline Quadrático & $4,66^{*}$ & $5,15^{*}$ & $0,60^{\text {ns }}$ & $0,48^{\text {ns }}$ \\
\hline Desvio regressão & $0,85^{\text {ns }}$ & $0,04^{\text {ns }}$ & $0,72^{\text {ns }}$ & $0,30^{\text {ns }}$ \\
\hline
\end{tabular}

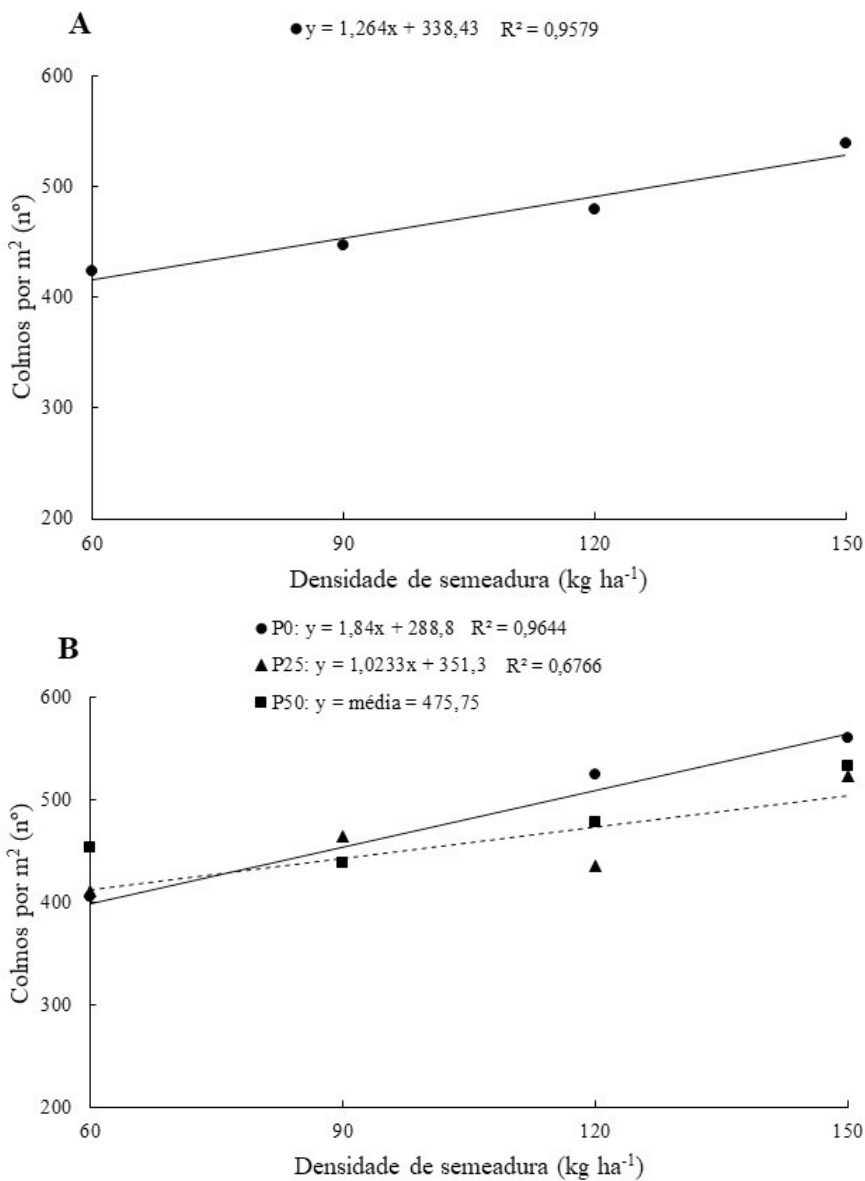

Figura 2. Número de colmos por metro quadrado em função da densidade de semeadura (A) e em cada dose de adubação (B). Pouso Redondo, SC, 2016/2017.

semeadura foi elevada. $\mathrm{O}$ oposto foi descrito por Marzari et al. (2007), relatando que o aumento da população de plantas promoveu redução no número de colmos por planta e do número de grãos por panícula, o que possivelmente aconteceu em decorrência do aumento da competição interespecífica. Mariot et al. (2003) também constataram que o incremento na densidade de semeadura reduziu o número de perfilhos por planta e de grãos formados por panícula.

A resposta linear positiva se repetiu para a densidade de semeadura nas doses de 0 e $25 \mathrm{~kg} \mathrm{ha}^{-1}$ de $\mathrm{P}_{2} \mathrm{O}_{5}$ (Figura 2B). Contudo, o número de colmos por $\mathrm{m}^{2}$ não apresentou 
resposta quando se utilizou a recomendação completa de fósforo ( $50 \mathrm{~kg} \mathrm{ha}^{-1}$ de $\mathrm{P}_{2} \mathrm{O}_{5}$ ), com média de 475,75 colmos por $\mathrm{m}^{2}$. Ou seja, onde se realizou a adubação fosfatada seguindo as recomendações da Sosbai (2016) não se observou ganhos significativos no número de colmos com o aumento na densidade de semeadura. A dependência entre densidade de semeadura e número de colmos por área já era esperada nos tratamentos com redução na adubação fosfatada, já que a deficiência deste elemento compromete o perfilhamento do arroz irrigado, sendo que em condições onde os teores de fósforo no solo são muito baixo $\left(\mathrm{P}<2,0 \mathrm{mg} \mathrm{dm}^{-3}\right)$ as plantas podem não perfilhar (Fageria et al., 2013). Plantas de arroz que desenvolvem em condição de baixa disponibilidade de fósforo no solo tem o crescimento da parte aérea comprometido, em função da redução na biomassa acumulada na parte aérea, do número de perfilhos, da altura de plantas e no teor de fósforo na parte aérea (Vejchasarn et al., 2016).

A densidade de semeadura foi expressa de forma linear e positiva com a variável número de panículas por $\mathrm{m}^{2}$, de modo que cada kg de semente acrescido a densidade de semeadura contribuiu com 1,1267 panículas (Figura 3A). Resposta semelhante ocorreu nos tratamentos que não receberam adubação fosfatada, com ganho de 1,91 panículas por kg de semente adicionado (Figura 3B). A correlação positiva entre

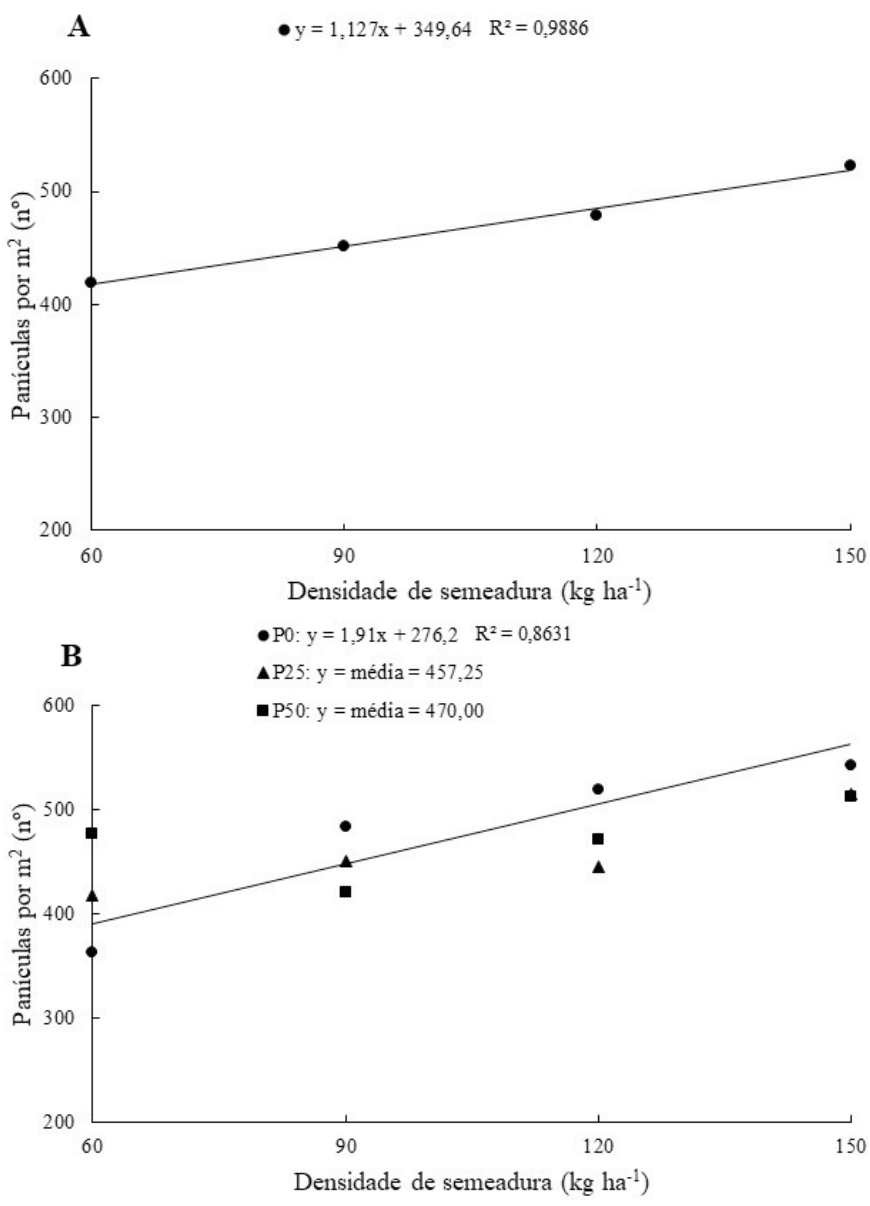

Figura 3. Número de panículas por metro quadrado em função da densidade de semeadura (A) e em cada dose de adubação (B). Pouso Redondo, SC, 2016/2017. densidade de semeadura e panículas por $\mathrm{m}^{2}$ já era esperada, pois está diretamente relacionada a população de plantas, estando estes resultados de acordo com os relatados por Marzari et al. (2007), que constataram que o aumento na densidade de semeadura também provocou acréscimos no número de panículas por metro quadrado.

Já nos tratamentos que receberam metade ou toda a recomendação de adubação fosfatada não se observou efeito da densidade de semeadura no número de panículas por $\mathrm{m}^{2}$, mantendo a média de 457,25 e 470 panículas $\mathrm{m}^{-2}$, respectivamente. Esta variação nos resultados com a adubação fosfatada pode estar relacionada ao fato do fósforo contribuir com o aumento no número de perfilhos por planta (Nascente et al., 2014), o que pode ter reduzido a importância da densidade de semeadura na definição do número panículas por área.

Os resultados de número de colmos e panículas por $\mathrm{m}^{2}$ estão de acordo com o descrito por Fageria et al. (2013), que relataram que as variáveis perfilhamento, biomassa seca da parte aérea e número de panículas foram variáveis favorecidas pela adubação fosfatada, além apresentarem contribuição dominante no aumento de produtividade de grãos, já que a produtividade de grãos é função do número de panículas por área, número de espiguetas por panícula, massa se mil grãos e esterilidade de espiguetas, por isso é muito importante entender as práticas de manejo que influenciam os componentes de produção e consequentemente a produtividade de grãos (Fageria et al., 2011).

Os fatores densidade de semeadura e doses de adubação fosfatada não influenciaram de maneira significativa na produtividade de grãos (Tabela 3). Entretanto, observa-se uma coerência com os resultados anteriores, mantendo-se a superioridade na produtividade de grãos com as doses de $25 \mathrm{e}$ $50 \mathrm{~kg} \mathrm{ha}^{-1}$ de $\mathrm{P}_{2} \mathrm{O}_{5}$ (Figura 4). Ressalta-se que não se observou sobreposição dos intervalos de segurança. Em sua pesquisa, Reis et al. (2018) também concluíram que em solo de baixa fertilidade ( $P$ de 3,0 e $3,1 \mathrm{mg} \mathrm{kg}^{-1}$ ), a adubação fosfatada contribui com o aumento de produtividade do arroz irrigado.

Observou-se resposta quadrática no peso de mil grãos em função do aumento da densidade de semeadura, alcançando o valor máximo de 32,62 g na densidade de semeadura de $111 \mathrm{~kg} \mathrm{ha}^{-1}$ (Figura 5A). Esses resultados são contrários aos observados por Marzari et al. (2007), que não verificaram o efeito da população de plantas sobre o peso de mil grãos.

Comportamento semelhante se repetiu no desdobramento da densidade de semeadura para a dose $0 \mathrm{~kg} \mathrm{ha}^{-1}$ de $\mathrm{P}_{2} \mathrm{O}_{5^{\prime}}$,

Tabela 3. Produtividade ( $\mathrm{kg} \mathrm{ha}^{-1}$ ) em função da densidade de semeadura e adubação fosfatada. Pouso Redondo, SC, 2016/2017.

\begin{tabular}{cccc}
\hline $\begin{array}{c}\text { Densidade } \\
\text { (kg ha }\end{array}$ & \multicolumn{3}{c}{ Dose $\mathrm{P}_{\mathbf{2}} \mathrm{O}_{\mathbf{5}} \mathbf{~ k g ~ h a}^{-1}$} \\
\cline { 2 - 4 } & $\mathbf{0}$ & $\mathbf{2 5}$ & $\mathbf{5 0}$ \\
\hline 60 & 8098 & 9165 & 8177 \\
90 & 8167 & 8817 & 8187 \\
120 & 7839 & 8742 & 8978 \\
150 & 8622 & 8327 & 8482 \\
$\mathrm{CV}(\%)$ & & 9,21 & \\
\hline
\end{tabular}




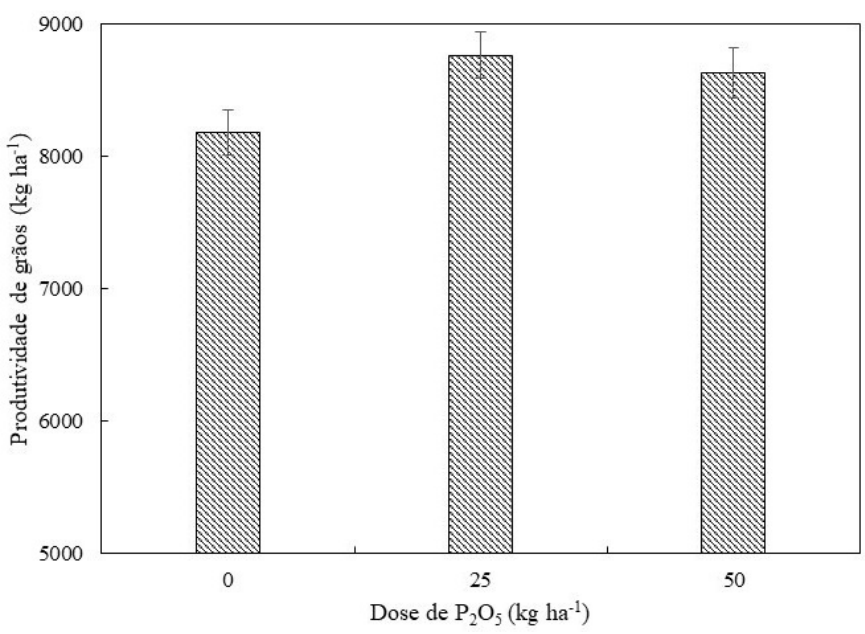

Figura 4. Produtividade $\left(\mathrm{kg} \mathrm{ha}^{-1}\right)$ em função da adubação fosfatada. Barras indicam o intervalo de confiança ao redor da média $(p<0,05)$. Pouso Redondo, SC, 2016/2017.

atingindo o peso máximo de $33,57 \mathrm{~g}$ na densidade de semeadura de $115,79 \mathrm{~kg} \mathrm{ha}^{-1}$ (Figura 5B). No entanto, a densidade de semeadura não influenciou o peso de mil grãos quando se utilizou as doses de 25 e $50 \mathrm{~kg} \mathrm{ha}^{-1}$ de $\mathrm{P}_{2} \mathrm{O}_{5}$, com média de 32,06 e $32,08 \mathrm{~g}$, respectivamente.

A ausência de resposta a densidade de semeadura para a variável peso de mil grãos nas doses de 25 e $50 \mathrm{~kg} \mathrm{ha}^{-1} \mathrm{de}$

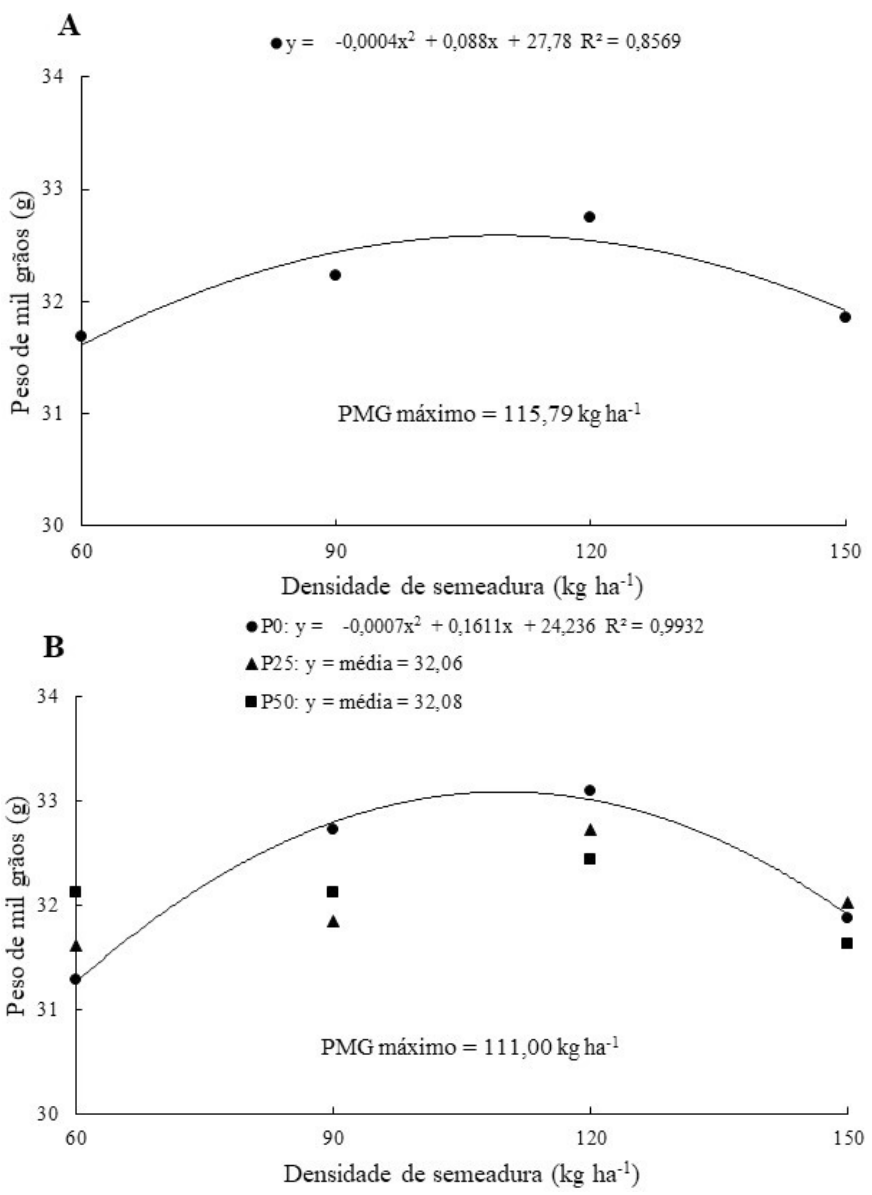

Figura 5. Peso de mil grãos em função da densidade de semeadura (A) e em cada dose de adubação (B). Pouso Redondo, SC, 2016/2017.
$\mathrm{P}_{2} \mathrm{O}_{5}$ pode estar relacionada ao papel deste elemento na etapa reprodutiva do arroz irrigado. Sabe-se que o fósforo é um elemento chave para a produtividade do arroz irrigado, segundo Reis et al. (2018), elevado teor de fósforo nos tecidos promove aumento no tamanho da panícula, no número de panículas, índice de colheita e produtividade de grãos. A quantidade de fósforo acumulada nos grãos chega a ser três vezes maior do que na parte aérea. Além disso, resultados de pesquisa determinaram que $69 \%$ de todo o fósforo acumulado na planta é translocado para os grãos e que a concentração de fósforo nos grãos tem correlação de $85 \%$ com a produtividade (Fageria et al., 2013). Desta forma, a ausência ou a redução da adubação fosfatada não atende sequer a exportação do fósforo, resultando em comprometimento ao enchimento dos grãos.

\section{Conclusão}

Os resultados indicaram resposta positiva da densidade de semeadura para os componentes de produção número de colmos por $\mathrm{m}^{2}$, número de panículas por $\mathrm{m}^{2}$ e o peso de mil grãos quando o arroz irrigado foi cultivado sem adubação fosfatada.

Não houve resposta a densidade de semeadura quando o arroz irrigado recebeu a dose recomendada de fósforo. A densidade de semeadura e a dose de fósforo não influenciaram a produtividade de grãos.

\section{Literatura Citada}

Brasil. Ministério da Agricultura, Pecuária e Abastecimento. Regras para análises de sementes. Brasília: Mapa; ACS, 2009. 399p.

Centro Nacional de Monitoramento e Alerta de Desastres Naturais - Cemaden. Estações pluviométricas. http://www.cemaden.gov. br/mapainterativo/\#. 17 Abr. 2019.

Companhia Nacional de Abastecimento - Conab. Acompanhamento safra brasileira: grãos, safra 2018/19, sétimo levantamento. Acompanhamento da safra brasileira de grãos, v. 6 - Safra 2018/19, n.7, p.1-69, 2019. https://www.conab.gov.br/info-agro/ safras/graos/boletim-da-safra-de-graos/item/download/25774_ f7f98ca710bc573075b0b3e7f6adf973. 17 Abr. de 2019.

Crusciol, C. A. C.; Mauad, M.; Alvarez, R. C. F.; Lima, E. V., Tiritan, C. $S$. Doses de fósforo e crescimento radicular de cultivares de arroz de terras altas. Bragantia, v. 64, n. 4, p. 643-649, 2005. https:// doi.org/10.1590/S0006-87052005000400014.

Empresa Brasileira de Pesquisa Agropecuária - Embrapa. Sistema brasileiro de classificação de solos. 3.ed. Brasília: Embrapa, 2013. $353 p$.

Empresa de Pesquisa Agropecuária e Extensão Rural de Santa Catarina - Epagri. Sistema de produção de arroz irrigado em Santa Catarina. 2.ed. Florianópolis: Epagri, 2015. 87p.

Fageria, N. K.; Barbosa Filho, M. P. Dry matter and grain yield, nutrient uptake, and phosphorus use efficiency of lowland rice as influenced by phosphorus fertilization. Communications in Soil Science and Plant Analysis, v. 38, n.9-10, p. 1289-1297, 2007. https://doi.org/10.1080/00103620701328537. 
Fageria, N. K.; Carvalho, G. D.; Santos, A. b.; Ferreira, E. P. B.; Knupp, A. M. Chemistry of lowland rice soils and nutrient availability. Communications in Soil Science and Plant Analysis, v.48, n.16, p.1913-1933, 2011. https://doi.org/10.1080/00103624.2011.59 1467.

Fageria, N. K.; Knupp, A. M.; Moraes, M. F. Phosphorus nutrition of lowland rice in tropical lowland soil. Communications in Soil Science and Plant Analysis, v. 44, n. 20, p. 2932-2940, 2013. https://doi.org/10.1080/00103624.2013.829485.

Lima, E. V.; Crusciol, C. A. C.; Mateus, G. P. Participação do colmo principal e dos afilhos na produtividade do arroz irrigado, em função da densidade de semeadura. Bragantia, v.69, n.2, p.387-393, 2010. https://doi.org/10.1590/s000687052010000200018.

Mariot, C. H. P.; Silva, P. R. F.; Menezes, V. G.; Teichmann, L. L. Resposta de duas cultivares de arroz irrigado à densidade de semeadura e à adubação nitrogenada. Pesquisa Agropecuária Brasileira, v. 38, n.2, p. 233-241, 2003. https://doi.org/10.1590/ S0100-204X2003000200010.

Marzari, V.; Marchezan, E.; Silva, L. S.; Camargo, E. R.; Teló, G. M. População de plantas, dose de nitrogênio e aplicação de fungicida na produção de arroz irrigado. I - Características agronômicas. Ciência Rural, v.37, n.2, p.330-336, 2007. https:// doi.org/10.1590/S0103-84782007000200006.

Nascente, A. S.; Lacerda, M. C.; Carvalho, M. C. S.; Mondo, V. H. V. Gypsum and phosphorus in the development of upland rice under a no-tillage system. African Journal of Agricultural Research, v. 9, n. 50, p. 3645-3654, 2014. https://doi.org/10.5897/ AJAR2014.8536.

Perecin, D.; Cargnelutti Filho, A. Efeitos por comparações e por experimento em interações de experimentos fatoriais. Ciência e agrotecnologia, v. 32, n. 1, p. 68-72, 2008. https://doi. org/10.1590/S1413-70542008000100010.
Reis, A. F. B.; Nascente, A. S.; Almeida, R. E. M.; Chagas Júnior, A. F. Growth and nutrient contents in lowland rice due to phosphorus and potassium fertilization. Pesquisa Agropecuária Tropical, v.48, n.2, p. 98-108, 2018. https://doi.org/10.1590/1983-40632018v4850666.

Sant'ana, E. P.; Sant'ana, E. V. P.; Fageria, N. K.; Freire, A. B. Utilização de fósforo e características do sistema radicular e da parte aérea da planta de arroz. Ciência e Agrotecnologia, v.27, n.2, p.370-381, 2003. https://doi.org/10.1590/S1413-70542003000200017.

Sartori, G. M. S.; Marchesan, E.; Luz, D. S.; Cassol, A. P. V.; Figueiredo, M. C. S.; Oliveira, M. A.; Silveira, M. V. E.; Ferreira, R. B. Manejo da adubação e seus efeitos na ocorrência de algas e na produtividade de arroz irrigado em áreas com residual de imidazolinonas. Ciência Rural, v.41, n.8, p.1323-1330, 2011. https://doi.org/10.1590/S0103-84782011000800005.

Silva, L. S.; Ranno, S. K.; Rhoden, A. C.; Santos, D. R.; Graupe, F. A. Avaliação de métodos para estimativa da disponibilidade de fósforo para arroz em solos de várzea do Rio Grande do Sul. Revista Brasileira de Ciência do Solo, v.32, n.1, p.207-216, 2008. https://doi.org/10.1590/S0100-06832008000100020.

Sociedade Sul-Brasileira do Arroz Irrigado - Sosbai. Arroz irrigado: recomendações técnicas da pesquisa para o Sul do Brasil. Pelotas: Sosbai, 2016. 200p.

Swarowsky, A.; Righes, A. A.; Marchezan, E.; Rhoden, A. C.; Gubiani, E. I. Concentração de nutrientes na solução do solo, sob diferentes manejos do arroz irrigado. Revista Brasileira de Engenharia Agrícola e Ambiental, v.10, n.2, p.344-351, 2006. https://doi. org/10.1590/S1415-43662006000200014 .

Vejchasarn, P.; Lynch, J. P.; Brown, K.M. Genetic variability in phosphorus responses of rice root phenotypes. Rice, v.9, e29, 2016. https://doi.org/10.1186/s12284-016-0102-9.

Wissuwa, M.; Ae, N. Genotypic variation for tolerance to phosphorus deficiency in rice and the potential for its exploitation in rice improvement. Plant Breeding, v.120, n.1, p.43-48, 2001. https:// doi.org/10.1046/j.1439-0523.2001.00561.x. 